\title{
SPECTRUM OF HEPATIC DYSFUNCTION IN DENGUE FEVER
}

K. P. Balaraj ${ }^{1}$, Vishwanath $\mathrm{K}^{2}$, Veena ${ }^{3}$, Vanitha ${ }^{4}$

\section{HOW TO CITE THIS ARTICLE:}

K. P. Balaraj, Vishwanath K, Veena, Vanitha. "Spectrum of Hepatic Dysfunction in Dengue Fever". Journal of Evolution of Medical and Dental Sciences 2014; Vol. 3, Issue 10, March 10; Page: 2533-2535,

DOI: $10.14260 /$ jemds/2014/2168

ABSTRACT: INTRODUCTION: Dengue infection is a common and major health problem across the globe and more so in India with its varied presentations and atypical parameters on investigations makes us to have more knowledge of these. MATERIALS AND METHODS: A total of 60 patients admitted to KIMS hospital and research centre, Bangalore with the confirmed diagnosis of dengue fever in 2013 were studied. RESULTS: An analysis of 60 confirmed cases of dengue showed that 70\% had hepatic dysfunction in form of raised SGOT [>2ULN], 60\% had SGPT [>2ULN], 3 had jaundice. All patients had fever; many patients had pain abdomen and vomiting as predominant complaint apart from myalgia. DISCUSSION: In our study mild to moderate hepatic dysfunction in the form of elevated enzymes were seen in most of the patients in consistent with other studies. Hepatic dysfunction was seen more in Patients with severe dengue infections similar to other studies. CONCLUSION: Thus it is necessary to have knowledge of this entity and diagnose early and start treatment to prevent the complications.

KEYWORDS: Dengue fever, hepatic dysfunction, SGOT, SGPT.

INTRODUCTION: Dengue infection is common and major health problem globally and more so in India. Estimates suggest that annually over 50 million cases of severe dengue occur in Asian countries with a case fatality rate of lesser than $5 \% .^{1}$ [The epidemic reaches its peak during the monsoon. Dengue viruses (DV) belong to family Flaviviridae and have four serotypes (1 to 4). They are transmitted mainly by the Aedes aegypti mosquito and also by Aedes albopictus Dengue infection is caused by any of the four antigenically related distinct serotypes. The presentations are varied and may present with atypical features ${ }^{2}$ may mimic other diseases thus delaying the diagnosis. Although dengue virus is a non-hepatotropic virus features of liver dysfunction can be seen in dengue ${ }^{3}$, and sometimes similar to hepatitis caused by other virus like Hep A and Hep B though with some differences thus it is essential to know about this entity which would help in early recognition of the disease

MATERIALS AND METHODS: A total of 60 patients [>18years] admitted to KIMS hospital and research centre, Bangalore with the confirmed diagnosis of dengue fever in 2013 were studied. Patients with mixed infections, chronic illness, and patients with known hepatic dysfunction, pregnant women, dengue like illness and chronic alcoholics were excluded from study. All the patients were subjected to detailed history, examination, complete blood counts, and liver function tests [routinely done in all suspected case of dengue].USG abdomen and chest X ray done where ever needed. Data of these patients admitted were analyzed for the profile of hepatic involvement in these patients

RESULTS: Of the 60 patients studied 38 were males. All the patients had fever as their predominant presenting complaint, vomiting seen in $83 \%$, generalized body ache in $75 \%$, pain abdomen in $50 \%$, 
petechial rash in $10 \%$ of patients. Hepatomegaly was seen in 20 [33\%] patients and splenomegaly in 10 [16\%] patients. The average platelet count was 56, 000. In LFT 42 [70\%] had raised SGOT [>2ULN], and 36 had high SGPT [>2ULN] raised total bilirubin was seen in 6 patients. In 2 patients SGOT was elevated 10 times the normal limit icterus was seen in 3 patients. 40[66\%] patients had ascites in USG and of which only 4 had clinically detectable free fluid. Serum albumin was normal in all patients and only one patient had elevated Prothrombin time. Other blood parameters included leucopenia seen in $30 \%$ of patients.

\begin{tabular}{|c|l|c|}
\hline SL no & \multicolumn{1}{|c|}{ PARAMETRS } & VALUES \\
\hline 1. & Average platelet count [per mm $\mathrm{mm}^{3]}$ & 56,000 \\
\hline 2. & Average serum bilirubin[mg/dl] & 0.8 \\
\hline 3. & Average SGOT[Units/L] & 106 \\
\hline 4. & Average SGPT[Units/L] & 80 \\
\hline 5. & SGOT[>2ULN] & $70 \%$ \\
\hline 6. & SGPT[>2ULN] & $60 \%$ \\
\hline 7. & Ascites seen in USG & $66 \%$ \\
\hline 8. & Leucopenia & $30 \%$ \\
\hline 9. & Hepatomegaly & $33 \%$ \\
\hline 10. & Splenomegaly & $16 \%$ \\
\hline \multicolumn{2}{|c|}{ TABLE SHOWING THE RESULTS OF STUDY } \\
\hline \multicolumn{2}{|c|}{} \\
\hline
\end{tabular}

DISCUSSION: All the patients presented with fever and 83\% had vomiting as their other predominant complaint apart from other symptoms like pain abdomen[50\%], myalgia[75\%] and few with petechial rash[10\%] similar to studies by Vaibhav Shukla ${ }^{4}$ and Srivenu Itha et al ${ }^{5}$

In our study mild to moderate hepatic dysfunction in the form of elevated enzymes were seen in most of the patients in consistent with other studies of Vaibhav Shukla and Srivenu Itha et al. There was a preferential elevation of SGOT compared with SGPT similar to study by Vaibhav Shukla, but no such difference was seen in study by Srivenu Itha et al. In two patients SGOT was seen to be elevated almost ten times the limit and all other causes of such high elevations of SGOT and SGPT were excluded.

Hepatic dysfunction was seen more in Patients with severe dengue infections similar to study done by Amitha Roy et al6. The mechanism of liver injury in DI remains unclear. Liver cells may be damaged through one or more of the following mechanisms: (i) direct cytopathic effect of the virus; (ii) killing of virus-infected cells by the host immune response; and (iii) a non-specific effect of shock and hypotension.

Hepatomegaly was seen in $33 \%$ and splenomegaly in $16 \%$ of patients though higher percentage of these was seen in above studies. Ascites was seen in nearly $66 \%$ of patients which were all mild detected by Ultrasonography and only 4 patients had clinically detectable free fluid. This finding has been attributed to excessive leakage of plasma in dengue also ascites has previously been reported in patients with acute viral hepatitis, ${ }^{7}$ and has been ascribed to increased portal pressure secondary to hepatocyte swelling and ballooning. ${ }^{8}$ A similar mechanism may be responsible for ascites in patients with Dengue infection. 
Leucopenia was seen in $30 \%$ of our patients and many times preceded the fall in platelet counts Leucopenia has been reported in many cases. ${ }^{9}$ Transient bone marrow suppression has been thought to be responsible for this. ${ }^{10}$ Only one patient in our study had prolonged PT.

CONCLUSIONS: Thus our study demonstrates it is very prudent to be alert regarding the hepatic dysfunction in dengue infection which may mimic a hepatitis picture more studies are needed regarding the prognostic value of these enzyme elevations and serotype of virus causing hepatic dysfunction and plausible explanation for preferential elevation of SGOT compared to SGPT.

\section{REFERENCES:}

1. World Health Organization. Dengue: Guideline for Diagnosis, Treatment, Prevention and Control. Geneva: World Health Organization; 2009.

2. Gulati S and Maheshwari. Atypical manifestations of dengue. Trop. Med. Int. Health 2007; 12: 1087-1095.

3. Seneviratne SL, Malavige GN, de Silva HJ. Pathogenesis of liver involvement during dengue viral infections. Trans R Soc Trop Med Hyg. 2006; 100:608-14.

4. Vaibhav Shukla, Ashok Chandra. A Study of Hepatic Dysfunction in Dengue. JAPI 2013.61:460461.

5. Srivenu Itha, Rajesh Kashyap, Narendra Krishnani, Vivek A. Saraswat, Gourdas Choudhuri, Rakesh Aggarwal. Profile of liver involvement in dengue. The National Medical Journal of India 2005:18[3].

6. Amrita Roy, Debalina Sarkar, Sohini Chakraborty, Jasodhara Chaudhuri, Pramit Ghosh, Swapna Chakraborty. Profile of Hepatic Involvement by Dengue Virus in Dengue Infected Children N Am J Med Sci. 2013 August; 5(8): 480-48.

7. Thomas FB, Fromkes JJ. Spontaneous bacterial peritonitis associated with acute viral hepatitis. J Clin Gastroenterol 1982; 4:259-62.

8. Lebrec D, Nouel O, Bernuau J, Rueff B, Benhamou JP. Portal hypertension in fulminant viral hepatitis. Gut 1980; 21:962-4.

9. Vinod H Ratageri, TA Shepur, PK Wasi, SC Chavan, IB Mujahid, PN Yergolkar Clinical profile and outcome of Dengue Fever Cases. Indian J Pediatr 2005; 72:705-06.

10. La Russa VF, Innis BL Mechanisms of Dengue Virus Induced bone marrow Suppression. Bailleres Clin Hematol 1995; 8:249-70.

\section{AUTHORS:}

1. K. P. Balaraj

2. Vishwanath K.

3. Veena

4. Vanitha

\section{PARTICULARS OF CONTRIBUTORS:}

1. Professor, Department of Medicine, KIMS.

2. Assistant Professor, Department of Medicine, KIMS.

3. Post Graduate, Department of Medicine, KIMS.

4. Post Graduate, Department of Medicine, KIMS.

\section{NAME ADDRESS EMAIL ID OF THE} CORRESPONDING AUTHOR:

Dr. Vishwanath K,

No. 598, $2^{\text {nd }}$ Main, $2^{\text {nd }}$ Stage,

Rajajinagar Block, Bangalore - 10 .

E-mail: vishu_ani@yahoo.com

Date of Submission: 13/02/2014.

Date of Peer Review: 14/02/2014.

Date of Acceptance: 22/02/2014.

Date of Publishing: 05/03/2014. 